\title{
New opportunities for developing tomato varieties with enhanced carotenoid content
}

\author{
Miguel Leiva-Brondo ${ }^{1}$, Mercedes Valcarcel ${ }^{2}$, Raúl Martí2, Salvador Roselló ${ }^{2}$, Jaime Cebolla-Cornejo ${ }^{\text {* }}$
}

\author{
'Universitat Politècnica de València/ Instituto Universitario \\ de Conservación y Mejora de la Agrodiversidad Valenciana \\ (Politechnic University of València/Institute for Conservation \\ and Improvement of Valencian Agrodiversity), Cno. de Vera, \\ $\mathrm{s} / \mathrm{n}-46022$ - Valencia - Spain. \\ 2University Jaume I - Dept. of Agrarian Sciences and Natural \\ Environment, Av. de Vicent Sos Baynat, s/n - 12071 - \\ Castellón - Spain. \\ *Corresponding author <jaicecor@btc.upv.es>
}

Edited by: Roberto Fritsche Neto

Received November 06, 2015

Accepted January 14, 2016

\begin{abstract}
The development of varieties with a high content of antioxidant compounds, such as carotenoids, has become a major focus in the marketing of tomato. Several mutants have been used in the development of high pigment varieties, but the significant influence of the environment on carotenoid content and the presence of negative side effects in vegetative growth and yield have limited the success of these variants. Consequently, the identification of alternative sources of variation in the quest for high carotenoid content is ongoing. In this study, 12 accessions of Solanum lycopersicum (including the former var cerasiforme) and S. pimpinelifolium have been evaluated in three different environments: open field and glasshouse cultivation at two sites. Three accessions (BGV6195 of S. pimpinellifolium, LA1423 of the former var cerasiforme and LA3633 a possible hybrid between S. pimpinellifolium and S. lycopersicum) showed outstanding and stable lycopene content, that doubled in all three environments the content of the positive control LA3538, with the high pigment-1 mutation (hp1). In addition, accession CATIE14812 would also be interesting as regards improvement of $\beta$-carotene content. These materials offer new opportunities in the development of tomato varieties with enriched and reliable carotenoid content and the close taxonomic relationship of these accessions with cultivated tomato will facilitate their use in breeding programs.

Keywords: Solanum lycopersicum, functional quality, lycopene, $\beta$-carotene, genetic resources
\end{abstract}

\section{Introduction}

The consumer is starting to value the role food can play in the improvement of their health and the reduction of the risk of disease beyond the conventional roles of nutrients or sensorial pleasures (Granato et al., 2010). The increasing cost of healthcare, life expectancy and the desire of older people to improve their life quality have reinforced the importance of this role (Roberfroid, 2007). One of the strategies pursued in the development of functional food is the concentration of bioactive substances in quantities higher than usual (Bigliardi and Galati, 2013).

Although not especially rich in vitamins and antioxidants, tomato has become an interesting source of antioxidants considering its high level of consumption (mean values of food supply in 2011 of 27.6 and $36.2 \mathrm{~kg} \mathrm{yr}^{-1}$ per capita in Europe and North America, respectively; source: FAO databases). As an example, in Spain tomatoes represent the first dietary source of lycopene, the second of vitamin $C$ and $\beta$-carotene and the third of vitamin E (García-Closas et al., 2004). In addition, tomato may also represent an important source of flavonols in the diet (Stewart et al., 2000). Consequently, tomato has demonstrated moderately strong evidence of clinical efficacy presumably because of its beneficial constituents (Sun-Waterhouse, 2011). In fact, the latest research highlights the relationship between the consumption of tomato and its products and a reduced risk of various maladies like obesity, hyperglycemic and hypercholesterolemic attributes, cardiovascular disorders, and cancer insurgences (Perveen et al., 2015).

Special attention has been focused on the carotenoid content and its effects on health. Higher lycopene dietary intake was inversely associated with total prostate cancer and with angiogenic potential, suggesting a reduction of the aggressive potential of prostate cancer ( $\mathrm{Zu}$ et al., 2014). The use of lycopene extracts as a supplement has been compared to the consumption of lycopene in the form of whole food sources, and it has been concluded that in the case of cardiovascular risk factors, tomato intake was more favorable with the exception of blood pressure management (Burton-Freeman and Sesso, 2014).

It is, therefore, of great interest to enhance the accumulation of carotenoids in tomatoes. Several mutants have been identified for this purpose, but the most efficient ones (high pigment mutations) have deleterious effects on agronomic performance (reviewed by Cebolla-Cornejo et al., 2013). In this context, the aim of this study was to evaluate germplasm in order to identify sources of variation with high carotenoid content.

\section{Materials and Methods}

\section{Plant materials}

Five Solanum lycopersicum L. cultivated accessions and ten accessions collected in the wild and belonging to the tomato wild ancestor Solanum pimpinellifolium L. and to the former variety cerasiforme of the cultivated species $S$. lycopersicum were studied (Table 1). Accession LA3633, despite being classified as the former cerasiforme variety of $S$. lycopersicum and later as possible $S$. pimpinellifolium in the Tomato Genetic Resource Center (TGRC, U.S.) database, showed intermediate traits between $S$. lycopersicum and S. pimpinellifolium. The origin of the accessions evaluated is as follows: PI accessions were provided by the Northeast Regional PI Station 
Table 1 - Characteristics and origin of the 15 tomato accessions evaluated for $\beta$-carotene and lycopene content.

\begin{tabular}{lcll}
\hline Accession & Species & \multicolumn{1}{c}{ Fruit characteristics } & Origin \\
\hline BGV2091 & Sl & Medium size, red & Girona, Spain \\
BGV12627 & Slc & Small size, red & Periera, Colombia \\
CATIE14817 & Slc & Small size, red & San Carlos, Guatemala \\
CATIE18628 & Slc & Small size, red & San José, Costa Rica \\
LA1289 & Slc & Small size, red & Junin, Peru \\
LA1423 & Slc & Small size, red & Pichincha, Ecuador \\
BGV4654 & Sp & Small size, red & Connectica, USA \\
BGV6195 & Sp & Small size, red & Cañar, Ecuador \\
CATIE14812 & Sp & Small, size red & San Carlos, Guatemala \\
PI365959 & Sp & Small size, red & Ancash, Peru \\
LA3633 & Slp & Small size, red & Ghana \\
LA3538 & Sl & Medium size, red, high carotenoid (hp1) & USA \\
CDP4777 & Slc & Small size, red, high $\beta$-carotene & Chiquimula, Guatemala \\
BGV5655 & Slc & Medium size, red, medium-high lycopene & Valencia, Spain \\
CDP8779 & SI & Big size, red, low carotenoid content & Spain \\
FORTUNA-C & Sl & Big size, red, reference in other studies & Spain \\
\hline
\end{tabular}

${ }^{1}$ SI: Solanum lycopersicum; SIc: S. Iycopersicum (former var. cerasiforme); Sp: S. pimpinellifolium; SIp: Possible cross between S. Iycopersicum and S. pimpinellifolium.

(U.S.), LA accessions were provided by the TGRC, CATIE accessions were provided by the Tropical Agricultural Research and Higher Education Center (CATIE, Costa Rica) and CDP and BGV accessions were provided by the Institute of Conservation \& Improvement of Valentian Agrodiversity (COMAV, Spain). Two breeding lines FORTUNA-C and CDP8779 (alias NE-1) were also provided by COMAV (Spain), and were included as a reference of standard to low carotenoid content considering results of previous studies. As references for high carotenoid content accession LA-3538, which carries the high pigment 1 , hp-1, gene (Jarret et al., 1984), and accession CDP4777, with high $\beta$-carotene content (Roselló et al., 2011, Adalid et al., 2012), were included. Finally, accession BGV5655 was also included as a traditional variety with intermediate lycopene content (Adalid et al., 2007).

\section{Experimental design and growing conditions}

A randomized complete block design was used with three blocks per environment, 15 plots per block (one per accession) and 3 plants per plot. Plants were cultivated in three different environments in order to check the stability of carotenoid accumulation. In Castellón (39 $59^{\prime} \mathrm{N}, 0^{\circ} 2^{\prime} \mathrm{W} 35 \mathrm{~m}$ asl) plants were cultivated in both a glasshouse and the open field. In Valencia (39 $28^{\prime} \mathrm{N}, 0^{\circ} 22^{\prime} \mathrm{W} 15 \mathrm{~m}$ asl) plants were cultivated in a glasshouse only. The growing cycle selected for all cases was spring-summer. In protected cultivation, heat dissipation systems (progressive shadowing and cooling) were used. Plants were staked and pruned properly and fertirrigation was applied following the usual regimes for the crop and the area. Air temperature and photosynthetically active radiation (PAR) were recorded using a weather station equipped with temperature, quantum light PAR sensors and data logger (Figure 1A).

\section{Sampling}

Fruits were harvested at the red-ripe stage (when fruits reached maximum color intensity) from the first three trusses. In small fruited populations at least 10 fruits per plant were sampled; otherwise four fruits were sampled per plant. Samples were blended at low light intensity and stored at $-20{ }^{\circ} \mathrm{C}$ until analysis.

\section{Lycopene and $\beta$-carotene determination}

Samples were thawed in the dark at $4^{\circ} \mathrm{C}$ and $100 \mathrm{mg}$ of the homogenate were extracted with $14 \mathrm{~mL}$ of a 8:6 v/v, ethanol/hexane solution at $4{ }^{\circ} \mathrm{C}$, for $24 \mathrm{~h}$ at $200 \mathrm{rpm}$ using a horizontal shaker. Hexane was complemented with 0.1 $\%$ butylated hydroxytoluene, (BHT). Hexane supernatant was separated and concentrated using a SpeedVac to complete dryness, and then re-suspended in $500 \mu \mathrm{L}$ of hexane containing $0.1 \%$ BHT. The sample was then filtered using a hydrophobic filter of $0.20 \mu \mathrm{m}$.

Lycopene and $\beta$-carotene were determined using reverse phase high performance liquid chromotography (HPLC), with the method reported by García-Plazaola and Becerril (1999) with slight modifications. Analyses were carried out on a 1200 series HPLC detector equipped with G1322A vacuum degasser, G1312A quaternary pump, G1329A standard autosampler, G1316 thermostated column compartment and G1315b diode array detector.

The chromatography was conducted in a column of reverse phase Zorbax ODS $(250 \times 4.6 \mathrm{~mm}$ i.d., $5 \mu \mathrm{m}$, particle size) protected by a guard column $(12.5 \times 4.6$ $\mathrm{mm}$ i.d., $5 \mu \mathrm{m}$ particle size). The mobile phase consisted of two components: solvent A with 84:9:7 v/v/v, acetonitrile/methanol/water and solvent $\mathrm{B}$ with $68: 32 \mathrm{v} / \mathrm{v}$, methanol/ethyl acetate. The injection volume was $40 \mu \mathrm{L}$. The sample was then eluted using a lineal gradient from $100 \%$ of solvent A to $100 \%$ of solvent B for $12 \mathrm{~min}$, followed by an isocratic elution of $100 \%$ of solvent B for 7 
A 5000
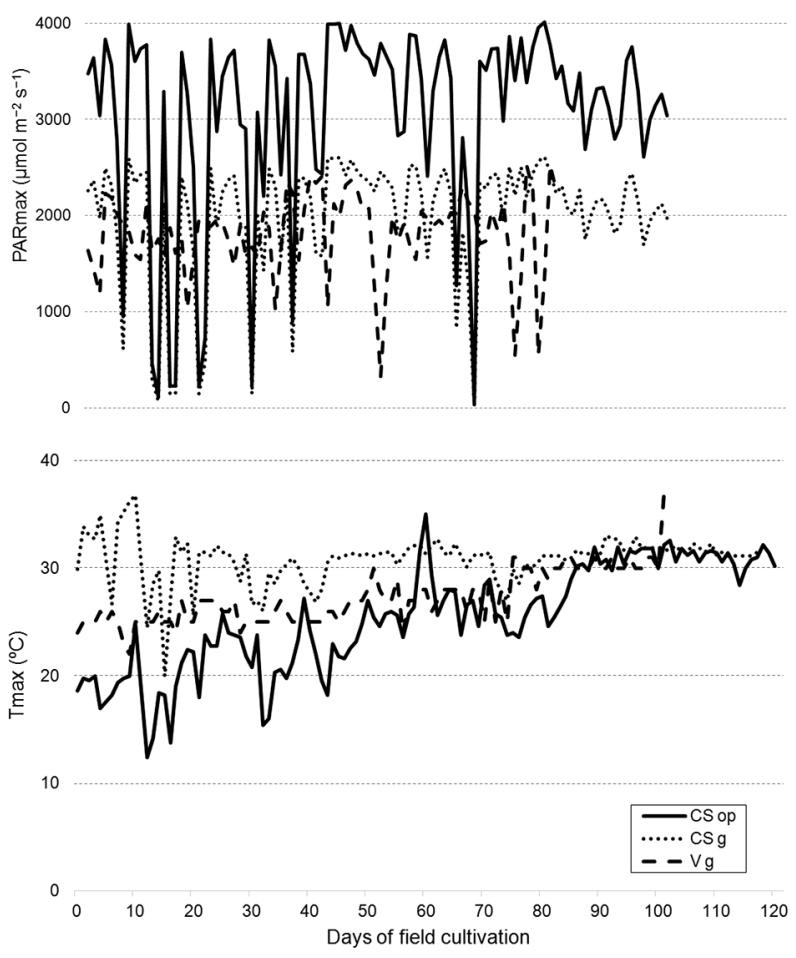

B

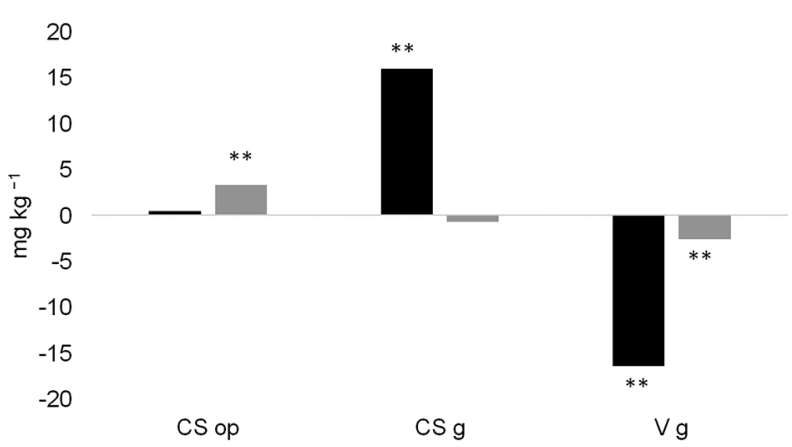

Figure 1 - (A) Maximum temperature and maximum photosynthetically active radiation (PAR) registered in the environments used for tomato cultivation. (B) Mean environmental predicted effect for lycopene and $\beta$-carotene accumulation in each of the environments tested. CS op: Castellón open field; CS g: Castellón glasshouse; V g: Valencia glasshouse. ${ }^{* *}$ Significant environmental effect (t-test; $p<0.01$ ).

min. Then, a lineal gradient was established from $100 \%$ of solvent B to $100 \%$ of solvent A for 1 min. Finally, an isocratic elution of $100 \%$ of solvent A was administered for $6 \mathrm{~min}$ to allow the column to re-equilibrate. The integration of the lycopene and $\beta$-carotene peaks was conducted at 470 and $445 \mathrm{~nm}$ respectively. The concentration of each item was computed using linear regressions using five solutions with variable concentrations of each component. The determination coefficient was higher than 0.99 in all cases. Each sample was analyzed twice. The results were reported as $\mathrm{mg} \mathrm{kg}^{-1}$ of fresh weight.

\section{Data analysis}

A mixed general linear model was used for the analysis of $\mathrm{i}$ genotype in $\mathrm{j}$ environment and $\mathrm{k}$ block inside environment $\mathrm{j}$ :

$Y_{i j k}=\mu+G_{i}+E_{j}+G_{i j}+B_{k(j)}+e_{i j k}$

where $\mathrm{Y}=$ phenotypic value (population mean $\mu$; variance $\left.\mathrm{V}_{\mathrm{p}}\right) ; \mathrm{G}=$ genotype effect $($ mean $=0$; variance $=$ $\left.\mathrm{V}_{\mathrm{G}}\right) ; \mathrm{E}=$ environment effect $\left(\right.$ mean $=0$; variance $\left.=\mathrm{V}_{\mathrm{E}}\right)$; $\mathrm{GE}=$ Genotype $\times$ Environment interaction effect $($ mean $=0$; variance $=\mathrm{V}_{\mathrm{G} \times \mathrm{E}} ; \mathrm{B}=$ the block effect $($ mean $=0$; variance $\left.=\mathrm{V}_{\mathrm{B}}\right)$; $\mathrm{e}=$ residual effect $($ mean $=0$; variance $\left.=\mathrm{V}_{\mathrm{e}}\right)$. All the factors were considered as random and the adjusted unbiased prediction (AUP) method (Zhu and Weir, 1996) was used to predict them. Standard errors of the statistics were obtained by the jackknife procedures (Miller, 1974; Zhu and Weir, 1996) and a two-tail t-test was performed for testing the significance of parameters obtained. The model was also recalculated considering the genotype as a fixed factor for mean performance accession comparison computing using the LSD method where $\alpha=0.05$. All the data analyses were performed with QGAStation (version 1) software.

\section{Results}

A wide range of lycopene and $\beta$-carotene accumulation was observed among the accessions and environments tested and even within the accession itself (Table 2). For both the accumulation of lycopene and $\beta$-carotene the block effect was not significant $(p>0.7)$ and this effect was discarded in the remaining statistical analysis. The observed phenotypic variation and the different trends of variation across environments indicated that the genotype and the genotype $x$ environment interaction would be important in the accumulation of carotenoids. Consequently, a deeper study of the effects of environment, genotype and genotype $\times$ environment interaction was performed, as the breeding value of the germplasm depends on the genetic potential.

\section{Environmental effect}

Contribution of the main environmental effect on phenotypic variance in lycopene $(10 \% \pm 1 \%)$ and $\beta$-carotene (9\% $\pm 1 \%$ accumulation) was estimated as significant $(p<0.001)$. This environmental effect was mainly attributed to temperature and photosyntetically active radiation (PAR) differences between the three environments evaluated (Figure 1). Shadowing used in the glasshouse as part of the heat dissipation systems almost halved the radiation compared with the open field (Figure 1A). Differences in PAR measured in the two glass- 
Table 2 - Phenotypic content (mean \pm standard error) in $\beta$-carotene and lycopene $\left(\mathrm{mg} \mathrm{kg}^{-1}\right)$ of 15 tomato accessions grown in three environments in Spain. The first five accessions are references for high (+), intermediate (+/-) or low (-) carotenoid content or have been studied for the accumulation of other bioactive compounds $(R)$.

\begin{tabular}{lccccccc}
\hline \multirow{2}{*}{ Accession } & \multicolumn{3}{c}{$\beta$-carotene $\left(\mathrm{mg} \mathrm{kg}^{-1}\right)$} & & \multicolumn{3}{c}{ Lycopene $\left(\mathrm{mg} \mathrm{kg}^{-1}\right)$} \\
\cline { 2 - 3 } & Castellón Open-field & Castellón Glasshouse & Valencia Glasshouse & & Castellón Open-field & Castellón Glasshouse & Valencia Glasshouse \\
\hline CDP8779 (-) & $16.64 \pm 2.85$ & $9.31 \pm 1.83$ & $8.15 \pm 2.35$ & & $46.27 \pm 6.59$ & $45.70 \pm 11.21$ & $37.43 \pm 10.80$ \\
FORTUNA-C (R) & $10.17 \pm 1.31$ & $9.61 \pm 1.64$ & $7.33 \pm 2.11$ & & $54.69 \pm 6.81$ & $85.10 \pm 17.56$ & $45.64 \pm 13.18$ \\
LA3538 (+) & $37.52 \pm 3.19$ & $25.57 \pm 5.30$ & $25.18 \pm 7.27$ & & $71.31 \pm 12.00$ & $107.06 \pm 17.84$ & $55.18 \pm 15.93$ \\
CDP4777 (+) & $23.28 \pm 2.63$ & $21.68 \pm 3.01$ & $25.32 \pm 7.31$ & & $48.30 \pm 4.97$ & $89.33 \pm 13.71$ & $66.08 \pm 19.07$ \\
BGV5655 (+/-) & $10.51 \pm 1.14$ & $7.23 \pm 1.40$ & $9.26 \pm 2.67$ & & $67.80 \pm 7.03$ & $69.15 \pm 13.38$ & $43.46 \pm 12.55$ \\
\hline PI365959 & $24.30 \pm 3.39$ & $21.88 \pm 3.69$ & $14.38 \pm 4.15$ & & $46.68 \pm 16.32$ & $82.98 \pm 20.03$ & $26.34 \pm 7.60$ \\
BGV12627 & $10.36 \pm 2.06$ & $8.84 \pm 1.59$ & $11.29 \pm 3.26$ & & $69.35 \pm 12.55$ & $65.34 \pm 10.87$ & $67.14 \pm 19.38$ \\
CATIE18628 & $22.69 \pm 1.80$ & $22.09 \pm 4.32$ & $17.53 \pm 5.06$ & & $58.81 \pm 5.47$ & $91.87 \pm 14.55$ & $71.46 \pm 20.63$ \\
CATIE14812 & $29.57 \pm 4.53$ & $32.97 \pm 4.82$ & $25.42 \pm 7.34$ & & $40.36 \pm 6.18$ & $92.76 \pm 12.55$ & $40.75 \pm 11.76$ \\
BGV6195 & $22.52 \pm 2.96$ & $14.83 \pm 1.93$ & $8.31 \pm 2.40$ & & $154.89 \pm 15.25$ & $164.92 \pm 22.91$ & $118.27 \pm 34.14$ \\
LA1289 & $14.05 \pm 1.90$ & $11.60 \pm 1.80$ & $10.85 \pm 3.13$ & & $70.64 \pm 9.01$ & $106.04 \pm 14.61$ & $43.55 \pm 12.57$ \\
LA3633 & $26.37 \pm 2.32$ & $9.11 \pm 1.88$ & $12.35 \pm 3.56$ & & $161.89 \pm 19.30$ & $119.72 \pm 20.41$ & $123.06 \pm 35.53$ \\
LA1423 & $21.88 \pm 2.34$ & $13.16 \pm 1.83$ & $12.08 \pm 3.49$ & & $147.64 \pm 16.33$ & $162.99 \pm 39.92$ & $121.47 \pm 35.07$ \\
CATIE14817 & $25.69 \pm 3.29$ & $18.80 \pm 1.35$ & $17.05 \pm 5.14$ & & $73.42 \pm 10.95$ & $72.40 \pm 11.68$ & $43.34 \pm 13.07$ \\
BGV2091 & $19.46 \pm 4.13$ & $21.70 \pm 2.48$ & $15.68 \pm 4.53$ & & $83.64 \pm 10.82$ & $68.96 \pm 17.85$ & $14.45 \pm 4.17$ \\
\hline
\end{tabular}

houses were also observed, radiation in Castellon-glasshouse being $20 \%$ higher than in Valencia-glasshouse. The maximum temperature in Castellon-glasshouse was considerably higher during the bulk of the cultivation cycle (Figure 1A). Between Valencia-glasshouse and Castellón-open field, maximum temperatures were higher in the former during the first third of the cultivation cycle.

The general mixed linear model used provided an estimation of the individual contribution of each of the three environments tested to the phenotypic expression of lycopene and $\beta$-carotene content (Figure 1B). The environmental conditions in Castellón-glasshouse (an average of maximum PAR radiation near $2000 \mu \mathrm{mol} \mathrm{m}^{-2} \mathrm{~s}^{-1}$ and average maximum temperature of $31^{\circ} \mathrm{C}$ ) were significantly the best for potentiating lycopene accumulation, while the conditions in Castellón-open field /an average of maximum PAR radiation near $3000 \mu \mathrm{mol} \mathrm{m} \mathrm{m}^{-2} \mathrm{~s}^{-1}$ and an average maximum temperature of $24^{\circ} \mathrm{C}$ ) significantly favored $\beta$-carotene accumulation. A negative effect was detected in the environmental conditions of Valenciaglasshouse (an average of maximum PAR radiation near $1150 \mu \mathrm{mol} \mathrm{m} \mathrm{m}^{-2} \mathrm{~s}^{-1}$ and average maximum temperature of $27^{\circ} \mathrm{C}$ ) for the accumulation of both carotenoids. The maximum environmental effect was higher in lycopene than in $\beta$-carotene (Figure 1 ), though the differences in relative values (considering the total mean value) were lower, $20 \%$ in the case of lycopene and $15 \%$ in the case of $\beta$-carotene.

\section{Genotype and genotype $\times$ environment interaction effects}

Both the genotype's main effect $(p<0.001)$ and the genotype $\times$ environment $(\mathrm{G} \times \mathrm{E})$ interaction $(p<0.001)$ made a significant contribution to phenotypic variance in lycopene and $\beta$-carotene accumulation. The main con- tribution was due to the genotype 's main effect $141 \%$ $\pm 1 \%$ for lycopene and $39 \% \pm 1 \%$ for $\beta$-carotene). Being considerably lower, the contribution of the genotype $\times$ environment interaction was not negligible $(5 \% \pm$ $1 \%$ both for lycopene and $\beta$-carotene). Consequently, the genetic merit of the accessions should be considered including both the genotype's main effect and the $\mathrm{G} \times$ E interaction.

For lycopene accumulation, the general linear mixed model provided an estimation of the significant contributions of total genotype $(\mu+G)$, and each interaction (Figure 2). CDP8779, a negative control with usually standard to low lycopene values showed, as expected, a low genotypic contribution. FORTUNA-C, used as a control in the analysis of other bioactive compounds, showed an intermediate total genotypic contribution. Positive controls CDP4777 and LA3538, which had previously shown medium to high lycopene content, showed total genotypic values compatible with the expectations. Considering the total genotypic contribution of the best and worst control, a range of variation was established in order to identify promising accessions (horizontal dashed lines in Figure 2).

CDP8779 and CDP4777 proved to be the most unstable controls showing important and significant contributions of the $\mathrm{G} \times \mathrm{E}$ interaction in two of the three environments tested (Figure 2). High lycopene LA3538, and intermediate lycopene CDP5665 were the most stable controls and showed no significant $\mathrm{G} \times \mathrm{E}$ interactions. In the case of FORTUNA-C only one significant contribution was found in Castellon open field.

Most of the accessions showed total genotypic contribution values for lycopene content in the range defined by the extreme positive and negative controls (Figure 2). Two of them, CATIE18628 and LA1289, 


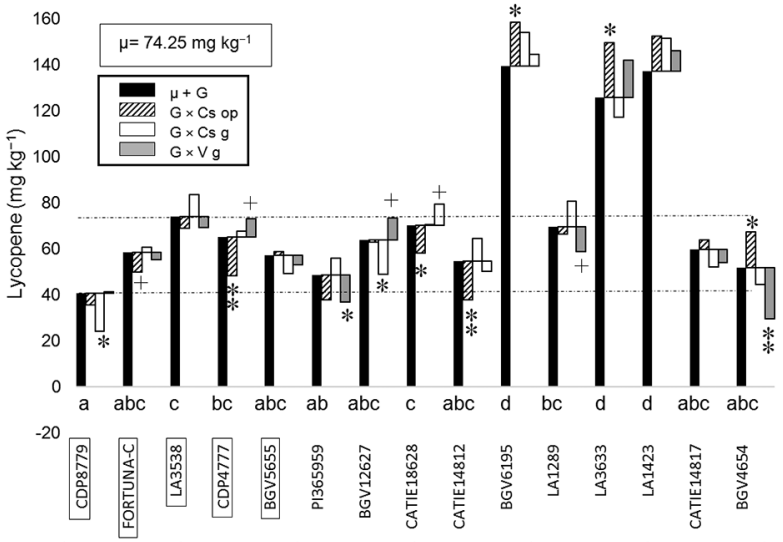

Figure 2 - Predicted total genotypic $(\mu+\mathrm{G})$ and interaction $(\mathrm{G} \times \mathrm{E})$ effects for lycopene accumulation in three environments: Cs op: Castellón open field, CS g: Castellón glasshouse, V g: Valencia glasshouse. First five accessions are controls. Reference line: higher genotypic value of controls (upper dashed line), lower genotypic value of controls (lower dashed line). Different letters indicate significant differences in total genotypic effect between accessions (LSD test, $p>0.05$ ). Significant departures from zero (t-test) are indicated with $+(p<0.1),{ }^{*}(p<0.05)$ and ${ }^{* *}(p<0.01)$.

showed a total genotypic effect similar to those of the high lycopene control. Accessions BGV6195, LA3633 and LA1423 showed a similar total genotypic effect that nearly doubled the value of the high lycopene control LA3538. Among these accessions, LA1423 showed higher stability, as it had no significant $\mathrm{G} \times \mathrm{E}$ interactions. BGV6195 and LA3633 showed a significant positive $G \times$ $\mathrm{E}$ interaction in Castellon open field that enhanced their total genotypic potential (Figure 2).

Regarding $\beta$-carotene accumulation, a wider range of variation was found between the control with the highest total genotypic contribution, LA3538, and the one with the lowest, FORTUNA-C (Figure 3). As in the case of lycopene accumulation, the relative contributions of interactions were considerably lower than the total genotypic contributions. The $\mathrm{G} \times \mathrm{E}$ interactions tended to decrease $\beta$-carotene in the case of the controls with lower accumulation and increase it in the controls with higher accumulation.

Among the accessions, only CATIE14812 showed a total genotypic contribution similar to the high carotenoid control LA3538 and significantly higher than the high $\beta$-carotene control CDP4777. Cultivation in Castellón glasshouse offered a significant $\mathrm{G} \times \mathrm{E}$ interaction that increased the potential $\beta$-carotene accumulation of CATIE14812.

\section{Discussion}

Some authors consider that lycopene content in tomato accession ranges between 78.3 and $181.2 \mathrm{mg} \mathrm{kg}^{-1}$, for low-content and high-content varieties respectively

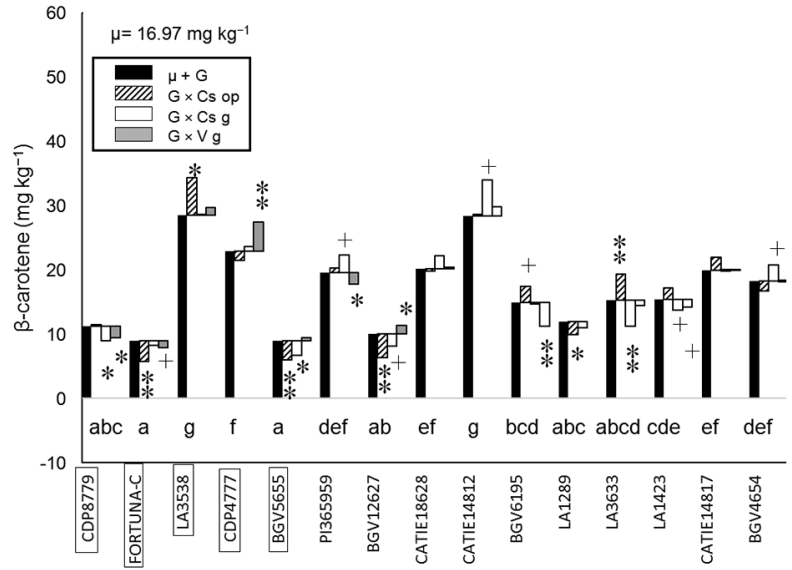

Figure 3 - Predicted total genotypic $(\mu+\mathrm{G})$ and interaction $(G \times$ E) effects for $\beta$-carotene accumulation in three environments: Cs op: Castellón open field, Cs g: Castellón glasshouse, V g: Valencia glasshouse First five accessions are controls. Reference line: higher genotypic value of controls (upper dashed line), lower genotypic value of controls (lower dashed line). Different letters indicate significant differences in total genotypic effect between accessions (LSD test, $p>0.05)$. Significant departures from zero (t-test) are indicated with $+(p<0.1),{ }^{*}(p<0.05)$ and ${ }^{* *}(p<0.01)$.

(Davies and Hobson, 1981; Klee and Giovannoni, 2011). However, other authors have reported that the most common average lycopene content of raw tomatoes is around $30 \mathrm{mg} \mathrm{kg}^{-1}$ (Holden et al., 1999; Kuti and Konu$\mathrm{ru}, 2005)$. Evidently, an important environmental effect is expected and considerable differences in lycopene accumulation have been identified in tomato cultivars grown in different countries (reviewed in Dumas et al., 2003). In Spain, widely grown hybrid cultivars such as 'Rambo', 'Daniella' and 'Durina' have shown contents ranging between 32, 36 and $65 \mathrm{mg} \mathrm{kg}^{-1}$ (Martínez-Valverde et al., 2002).

In this context, while screening for sources of variation of carotenoid content it is essential to include several controls in order to be able to compare results. The phenotypic average lycopene values obtained in previous trials for the low content control line, CDP8779, reached $90 \mathrm{mg} \mathrm{kg}^{-1}$ (Roselló et al., 2011), whereas in this work, the different environmental conditions contributed to diminish its lycopene content by $50 \%$. A similar reduction applied to the control with intermediate contents, BGV5655, which in the same publication reached up to $120 \mathrm{mg} \mathrm{kg}^{-1}$. In the case of the control CDP4777, a lower reduction in lycopene content was observed (around $25 \%$ ) compared with previous trials where it reached $104 \mathrm{mg} \mathrm{kg}^{-1}$ (Roselló et al., 2011). The control LA3538 had previously shown $94 \mathrm{mg} \mathrm{kg}^{-1}$ (Adalid et al., 2007); glasshouse cultivation in Valencia represented an important reduction compared with this value, though the differences in the other environments were lower. These results confirmed that the environment has indeed an important influence in lycopene accumulation, 
though the influence of different analytical procedures (spectrophotometry vs. HPLC) cannot be discarded. Additionally, it should be considered that all environments included in this study were sub-optimal and better performance is expected for the promising accessions identified.

Among the different environmental determinants for carotenoid accumulation, it has been described that lycopene content increases with temperature (Krumbein et al., 2006) and sun radiation (Dumas et al., 2003) until limiting conditions are reached (Hamauzu et al., 1998). In this sense, it has been reported that the rate of lycopene synthesis in tomato plants declines drastically with temperatures above $30-35{ }^{\circ} \mathrm{C}$ (Baqar and Lee, 1978), and is completely inhibited over $32^{\circ} \mathrm{C}$ in excised fruit (Tomes, 1963; Dumas et al., 2003). In this study, the maximum temperature was lower than the $32{ }^{\circ} \mathrm{C}$ threshold continuously through to the end of the cycle. Considering that average temperature in our conditions was lower than in previous studies (Roselló et al., 2011), sub-optimal temperatures could have resulted in lower lycopene accumulation. Accordingly, a considerable effect of temperature would explain higher lycopene accumulation in Castellón glasshouse, as this environment showed the highest temperatures, below the limit for lycopene synthesis. The worst performance observed in Valencia compared to Castellón open field would not be explained by a temperature effect, but rather by a radiation effect, as PAR in this environment was lower during the entire growing cycle. In this sense, Gautier et al. (2005) found that the content in lycopene and $\beta$-carotene increased with exposure to photosynthetic radiation, and Jarquín-Enríquez et al. (2013) observed that tomato fruit which received greater amounts of light accumulated more lycopene. It should be considered though, that Kläring and Krumbein (2013) found no effect of shading in the content of lycopene in tomatoes grown in greenhouses.

Although the effect of environment was quite important (maximum relative contribution compared to total mean contribution around $20 \%$ for lycopene and $15 \%$ for $\beta$-carotene), the effect of $\mathrm{G} \times \mathrm{E}$ interactions was not negligible and in some cases (eg. BGV0991 Castellón glasshouse) it reached more than $30 \%$ of the total mean contribution. The considerable effects of both environment and $\mathrm{G} \times \mathrm{E}$ interaction reinforce the need to develop multi-environmental trials when screening for sources of variation of functional compounds. This important effect was also observed for the accumulation of vitamin $\mathrm{C}$ in which the effect of $\mathrm{G} \times \mathrm{E}$ interaction was higher than the effect of environment (Leiva-Brondo et al., 2012). The importance of $\mathrm{G} \times \mathrm{E}$ interaction was also highlighted in screening trials for vitamin $\mathrm{C}$, carotenoids and polyphenols in traditional varieties of tomato (Cortés-Olmos el at., 2014).

Most of the accessions tested showed genotypic values for lycopene accumulation between those obtained with low and high accumulation control lines.
But outstanding values regarding lycopene contents were identified in three accessions (BGV6195, LA1423 and LA3633). The three accessions nearly doubled (1.9, 1.9 and 1.7 times respectively) the genotypic value of the positive control LA3538 that carries the high pigment-1, $h p-1$, mutation (Jarret et al., 1984) and nearly 2.5-fold the value of the low accumulation controls.

Several circumstances point to a different genetic control of increased lycopene accumulation identified in the promising lines compared to the high pigment control. The mutation $h p-1$ originated in 1917 in an undetermined S. lycopersicum variety (Kerr, 1965) and one of these lines, BGV6195 belongs to a different species: $S$. pimpinellifolium and LA3633, a possible crossing between the cultivated species and $S$. pimpinellifolium. Additionally, high pigment mutations result in increased content in $\beta$-carotene (Long et al., 2006), while the total genotypic contribution of these three accessions for $\beta$-carotene accumulation was considerably lower than in LA3538. It does not seem either that the high genotypic potential of the lines depends on the size of the fruit. It has been described that carotenoids accumulate differentially in the fruit, with more than 2-fold amounts of lycopene in the pericarp than in the locules and 4-fold higher amounts of $\beta$-carotene in the locules than in the pericarp (Davies and Hobson, 1981). Thus, accessions with reduced fruit size may benefit in lycopene accumulation considering the high ratios' fruit surface to volume. Although the three accessions identified with high lycopene content have reduced fruit size, as expected considering their taxonomy, they offer higher content than other accessions with similar sizes; thus the justification of high content should be different.

Accession LA1423 would be the more stable of these promising materials with no significant $\mathrm{G} \times \mathrm{E}$ interactions, though the only significant interaction in both LA3633 and BGV6195 would lead to higher lycopene content in the open field. LA1423 and LA3633 previously showed a high potential for vitamin $\mathrm{C}$ accumulation, though in that case LA1423 proved to be quite unstable (Leiva-Brondo et al., 2012).

As regards $\beta$-carotene accumulation, the average content of raw tomatoes has been reported to be in the range of 1.4 to $11.9 \mathrm{mg} \mathrm{kg}^{-1}$ (Davies and Hobson, 1981; Holden et al., 1999; Klee and Giovannoni, 2011). The average values of the low control lines obtained in this study were 6 and $11 \mathrm{mg} \mathrm{kg}^{-1}$ that are within this range, and the values are similar to those obtained in other assays under our conditions (Adalid et al., 2010; Roselló et al., 2011).

Among the evaluated accessions only CATIE14812 of $S$. pimpinellifolium showed a similar total genotypic contribution similar to the best control, LA3538 (28.4 vs. $\left.28.51 \mathrm{mg} \mathrm{kg}^{-1}\right)$. Again, as it belongs to a different species and does not accumulate high levels of lycopene, this seems to indicate that the control for such accumulation should be different. Whatsmore, it did not have an orange color. This phenotype would indi- 
cate an effect similar to the Beta mutant, which entails a mutation in the promoter of the CYC-B $\beta$-cyclase, increasing the level of transcription and resulting in increased levels of $\beta$-carotene at the expense of lycopene (reviewed by Cebolla-Cornejo et al., 2013). CATIE14812 also reached a $\beta$-carotene content higher than CDP 4777 which was previously described as a good material for the improvement of this carotenoid in tomato (Adalid et al., 2012).

\section{Conclusion}

Lycopene and $\beta$-carotene content varies widely according to the environment. Despite the instability, accessions BGV6195 of $S$. pimpinellifolium, LA1423 of $S$. lycopersicon var cerasiforme and LA3633, a possible hybrid between $S$. pimpinellifolium and S. lycopersicon var cerasiforme, have shown high genotypic potential for the improvement of lycopene content in new varieties of tomato targeted to quality markets appreciating the functional value of foods. The close relationship of these materials with cultivated tomato will enable a more efficient and rapid exploitation of their potential in breeding programs. Furthemore, the accession CATIE14812 of $S$. pimpinellifolium, will also have interest for the improvement of $\beta$-carotene.

\section{References}

Adalid, A.M.; Roselló, S.; Nuez, F. 2007. Breeding for nutritional quality in tomato: new sources of variability for high carotenoid and vitamin $\mathrm{C}$ content $=$ Mejora de la calidad nutritiva en tomate: búsqueda de nuevas fuentes de variabilidad con alto contenido en carotenoides y vitamina C). Actas de Horticultura 48: 121-124 (in Spanish).

Adalid, A.M.; Roselló, S.; Nuez, F. 2010. Evaluation and selection of tomato accessions (Solanum section Lycopersicon) for content of lycopene, $\beta$-carotene and ascorbic acid. Journal of food composition and analysis 23: 613-618.

Adalid, A.M.; Roselló, S.; Valcárcel, M.; Nuez, F. 2012. Analysis of the genetic control of $\beta$-carotene and 1-ascorbic acid accumulation in an orange-brownish wild cherry tomato accession. Euphytica 184: 251-263.

Baqar, M.R.; Lee, T.H. 1978. Interaction of CPTA and high temperature on carotenoid synthesis in tomato fruit. Zeitschrift für Pflanzenphysiologie 88: 431-435

Bigliardi, B.; Galati, F. 2013. Innovation trends in the food industry: the case of functional foods. Trends in Food Science \& Technology 31: 118-129.

Burton-Freeman, B.; Sesso, H.D. 2014. Whole food versus supplement: comparing the clinical evidence of tomato intake and lycopene supplementation on cardiovascular risk factors. Advances in Nutrition 5: 457-485.

Cebolla-Cornejo, J.; Roselló, S.; Nuez, F. 2013. Selection of tomato rich in nutritional terpenes. p. 2853-2881. In: Ramawat, K.G.; Mérillon, J.M., eds. Natural products: phytochemistry, botany and metabolism of alkaloids, phenolics and terpenes. Springer, Berlin, Germany.
Cortés-Olmos, C.; Leiva-Brondo, M.; Roselló, J.; Raigón, M.D.; Cebolla-Cornejo, J. 2014. The role of traditional varieties of tomato as sources of functional compounds. Journal of the Science of Food and Agriculture 94: 2888-2904.

Davies, J.N.; Hobson, G.E. 1981. The constituents of tomato fruit-the influence of environment, nutrition, and genotype. Critical Reviews in Food Science and Nutrition 15: 205-280.

Dumas, Y.; Dadomo, M.; Di Lucca, G.; Grolier, P. 2003. Effects of environmental factors and agricultural techniques on antioxidantcontent of tomatoes. Journal of the Science of Food and Agriculture 83: 369-382.

García-Closas, R.; Berenguer, A.; Tormo, M.J.; Sánchez, M.J.; Quiros, J.R.; Navarro, C.; Arnaud, R.; Dorronsoro, M.; Chirlaque, M.D.; Barricarte, A. 2004. Dietary sources of vitamin $\mathrm{C}$, vitamin $\mathrm{E}$ and specific carotenoids in Spain. British Journal of Nutrition 91: 1005-1011.

García-Plazaola, J.I.; Becerril, J.M. 1999. A rapid highperformance liquid chromatography method to measure lipophilic antioxidants in stressed plants: simultaneous determination of carotenoids and tocopherols. Phytochemical Analysis 10: 307-313.

Gautier, H.; Rocci, A.; Buret, M.; Grasselly, D.; Dumas, Y.; Causse, M. 2005. Effect of photoselective filters on the physical and chemical traits of vine-ripened tomato fruits. Canadian Journal of Plant Science 85: 439-446.

Granato, D.; Branco, G.F.; Nazzaro, F.; Cruz, A.G.; Faria, J.A.F. 2010. Functional foods and nondairy probiotic food development: trends, concepts, and products. Comprehensive Reviews in Food Science and Food Safety 9: 292-302.

Hamauzu, Y.; Chachin, K.; Ueda, Y. 1998. Effect of postharvest temperature on the conversion of $14 \mathrm{C}$-mevalonic acid to carotenes in tomato fruit. Journal of the Japanese Society for Horticultural Science 67: 549-555.

Holden, J.M.; Eldridge, A.L.; Beecher, G.R.; Buzzard, I.M.; Bhagwat, S.; Davis, C.S.; Douglass, L.W.; Gebhardt, S.; Haytowitz, D.; Schakel, S. 1999. Carotenoid content of US foods: an update of the database. Journal of Food Composition and Analysis 12: 169-196.

Jarquín-Enríquez, L.; Mercado-Silva, E.; Maldonado, J.; LopezBaltazar, J. 2013. Lycopene content and color index of tomatoes are affected by the greenhouse cover. Scientia Horticulturae 155: 43-48.

Jarret, R.L.; Sayama, H.; Tigchelaar, E.C. 1984. Pleiotropic effects associated with the chlorophyll intensifier mutations high pigment and dark green in tomato. Journal of the American Society for Horticultural Science 109: 873-878.

Kerr, E. 1965. Identification of high-pigment, hp, tomatoes in the seedling stage. Canadian Journal of Plant Science 45: 104-105.

Kläring, H.; Krumbein, A. 2013. The effect of constraining the intensity of solar radiation on the photosynthesis, growth, yield and product quality of tomato. Journal of Agronomy and Crop Science 199: 351-359.

Klee, H.J.; Giovannoni, J.J. 2011. Genetics and control of tomato fruit ripening and quality attributes. Annual Review of Genetics 45: 41-59.

Kuti, J.O.; Konuru H.B. 2005. Effects of genotype and cultivation environment on lycopene content in red-ripe tomatoes. Journal of the Science of Food and Agriculture 85: 2021-2026. 
Leiva-Brondo, M.; Valcárcel, M.; Cortés-Olmos, C.; Roselló, S.; Cebolla-Cornejo, J.; Nuez, F. 2012. Exploring alternative germplasm for the development of stable high vitamin C content in tomato varieties. Scientia Horticulturae 133: 84-88.

Long, M.; Millar, D.J.; Kimura, Y.; Donovan, G.; Rees, J.; Fraser, P.D.; Bramley, P.M.; Bolwell, G.P. 2006. Metabolite profiling of carotenoid and phenolic pathways in mutant and transgenic lines of tomato: identification of a high antioxidant fruit line. Phytochemistry 67: 1750-1757.

Martínez-Valverde, I.; Periago, M.J.; Provan, G.; Chesson, A. 2002. Phenolic compounds, lycopene and antioxidant activity in commercial varieties of tomato (Lycopersicum esculentum). Journal of the Science of Food and Agriculture 82: 323-330.

Miller, R.G. 1974. The jacknife: a review. Biometrika 61: 1-15.

Perveen, R.; Suleria, H.A.R.; Anjum, F.M.; Butt, M.S.; Pasha, I.; Ahmad, S. 2015. Tomato (Solanum lycopersicum) carotenoids and lycopenes chemistry: metabolism, absorption, nutrition, and allied health claims; a comprehensive review. Critical Reviews in Food Science and Nutrition 55: 919-929.

Roberfroid, M.B. 2007. Concepts and strategy of functional food science: the European perspective. The American Journal of Clinical Nutrition 71: 1660-1664.
Roselló, S.; Adalid, A.M.; Cebolla-Cornejo, J.; Nuez, F. 2011. Evaluation of the genotype, environment and their interaction on carotenoid and ascorbic acid accumulation in tomato germplasm. Journal of the Science of Food and Agriculture 91: 1014-1021.

Stewart, A.J.; Bozonnet, S.; Mullen, W.; Jenkins, G.I.; Lean, M.E.; Crozier, A. 2000. Occurrence of flavonols in tomatoes and tomato-based products. Journal of Agricultural and Food Chemistry 48: 2663-2669.

Sun-Waterhouse, D. 2011. The development of fruit-based functional foods targeting the health and wellness market: a review. International Journal of Food Science and Technology 46: 899-920.

Tomes, M.L. 1963. Temperature inhibition of carotene synthesis in tomato. Botanical Gazette: 180-185.

Zhu, J.; Weir, B. 1996. Diallel analysis for sex-linked and maternal effects. Theoretical and Applied Genetics 92: 1-9.

Zu, K.; Mucci, L.; Rosner, B.A.; Clinton, S.K.; Loda, M.; Stampfer, M.J.; Giovannucci, E. 2014. Dietary lycopene, angiogenesis, and prostate cancer: a prospective study in the prostatespecific antigen era. Journal of the National Cancer Institute 106: djt430. 